\title{
ENÁRGEIA E ELEGIA GREGA ARCAICA
}

\author{
RAFAEL BRUNHARA*
}

Universidade Federal do Rio Grande do Sul

\begin{abstract}
Resumo. Este texto apresenta dois objetivos: primeiro, visa demonstrar como a noção de Enárgeia, fundada e elaborada na tradição retórica grega do séc. V, está presente na poesia grega desde os poemas homéricos. Em seguida, visa compreendê-la no âmbito da elegia grega arcaica simposial, sobretudo na produção do poeta espartano Tirteu.

Palavras-Chave. Tirteu; elegia; simpósio; Homero.
\end{abstract}

D.o.I. 10.11606/issn.2358-3150.v19i2p43-54

Quando Plutarco, em sua obra Glória dos Atenienses, Põe-se a falar de Tucídides $\left(347^{\mathrm{a}}-\mathrm{C}\right)$, sublinha a habilidade exímia do historiógrafo ateniense em elaborar descrições extremamente vívidas, como se colocassem o leitor diante dos acontecimentos narrados, ${ }^{1}$ e relembra a máxima notória que teria sido proferida pelo poeta arcaico Simônides de Céos (c.556-468 a.C.), "pintura é poesia silenciosa, poesia é pintura falante $(346 \mathrm{f})$ ". ${ }^{2}$ Por esse aforismo, que perpassará boa parte das reflexões dos antigos acerca de poesia, temos a mais clara indicação de que a poesia era entendida, já desde o período arcaico, como um processo intenso de visualização, ou, em outras palavras, um discurso que tem como requisito fundamental a produção de enárgeia (غ̉vá $\rho \gamma \varepsilon ı \alpha, " v i v i d e z ")$.

Assim sendo, este texto verificará primeiramente de que modo a noção da enárgeia, conceituada e explorada no bojo da tradição retórica da Grécia do século v a.C, já está presente na poesia grega desde os poemas

Professor de Língua e Literatura Grega na Universidade Federal do Rio Grande do Sul e doutorando junto ao programa de pós-graduação em Letras Clássicas da Universidade de São Paulo.

" Artigo recebido em 05.set.2016 e aceito para publicação em 25.out.2016.

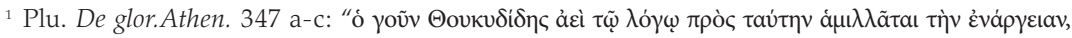

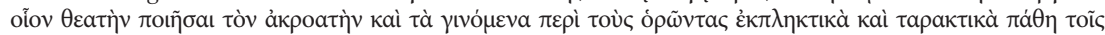

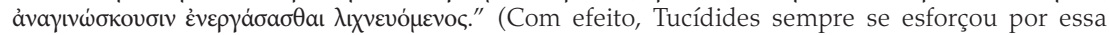
vividez (enárgeia) em sua narrativa, como se fizesse do ouvinte um espectador, ávido que era em produzir nos seus leitores as [mesmas] sensações maravilhosas e perturbadoras [sentidas] por aqueles que viram os eventos). Tradução nossa.

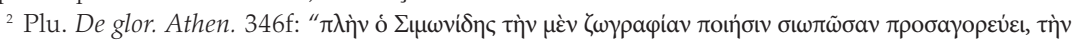

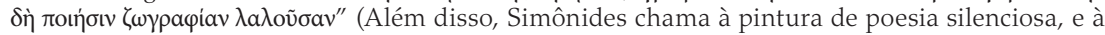
poesia de pintura falante). 
homéricos. Em seguida, visa compreendê-la no âmbito da chamada elegia grega arcaica simposial: buscando exemplos na produção elegíaca do poeta espartano Tirteu (c.640 a.C.), perseguiremos a hipótese de que a enárgeia não só é uma característica intrínseca do discurso poético, como também é um expediente profícuo na performance dos poemas arcaicos simposiais, dada a sua capacidade de evocar e tornar presente aos olhos do ouvinte um cenário distante do contexto original de apresentação do poema. Por fim, tece-se uma comparação entre a maneira que os poemas de Tirteu e de Homero apresentam a enárgeia.

\section{ENÁRGEIA E POESIA GREGA ARCAICA: O CASO DE HOMERO}

A capacidade de causar na audiência o efeito de visualização que marca a enárgeia revela-se como um dos principais fatores para distinguir o bom rapsodo do mau, se levarmos em conta o que é dito no diálogo Íon, de Platão: na passagem, Sócrates interroga o rapsodo Íon acerca de sua inspiração poética, e se quando ele recita os versos de Homero, sua alma está possuída e julga-se presente nas situações que os versos requerem ( 535 b-c). Diante da resposta afirmativa do rapsodo, Sócrates questiona (535 d-e):

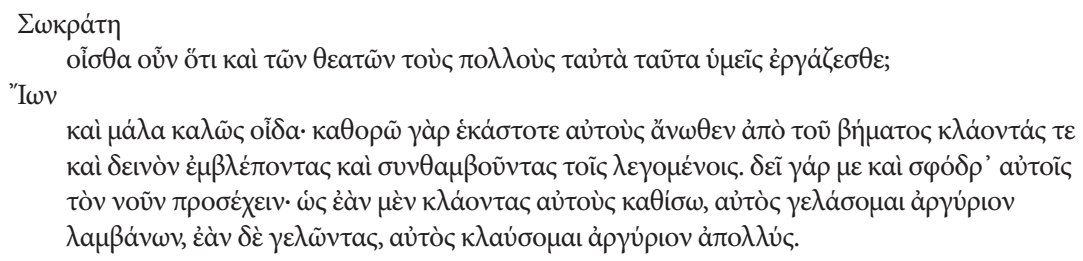

\section{Sócrates}

E você sabe que vocês [rapsodos] também provocam essas mesmas coisas na Íon maioria dos espectadores?

E sei muitíssimo bem! Toda vez, do alto do estrado, eu os vejo embaixo chorando, com um olhar terrível, se espantando com as coisas ditas. E é preciso que eu preste atenção neles - e como! -, porque, se os deixar chorando, eu mesmo vou rir ao receber o pagamento; mas, se os deixar rindo, perdendo o pagamento, eu mesmo vou chorar... ${ }^{3}$ 
Desde a Antiguidade, é notória a importância dada à qualidade gráfica da poesia homérica, ${ }^{4}$ seu poder de colocar as ações e os seus participantes diante dos olhos dos ouvintes e envolvê-los na ação épica. Já nos próprios versos homéricos o aedo é concebido antes como uma testemunha ocular dos acontecimentos, e a narração como uma descrição de eventos vistos, os quais ele descreve com tamanha vividez que parece estar presente nos mesmos.

Nesse sentido, são famosos os versos que abrem a segunda Invocação às Musas na Ilíada. As Deusas Musas são capazes de narrar com pre-

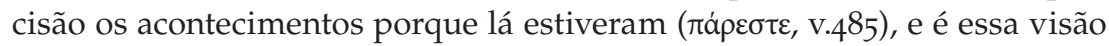
privilegiada que elas transmitem ao aedo (Il.2.484-6):

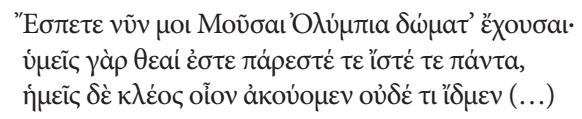

Dizei-me agora, Musas que habitam a Olímpia morada, Pois vós sois Deusas, vós estais presentes e tudo sabeis, mas nós, ouvimos apenas a fama e nada sabemos $(\ldots)^{5}$

A Odisseia, que no canto viII refletirá sobre a própria composição épica na figura do bardo Demódoco, também comprova essa habilidade do poeta no elogio feito por Odisseu (Od. 8.487-91):

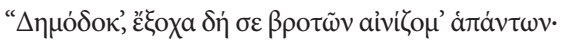

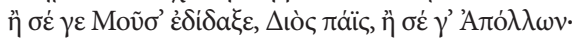

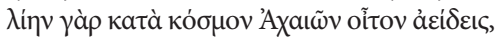

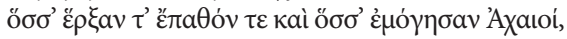

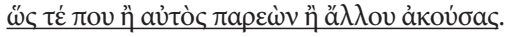

Demódoco, bem acima dos mortais todos te louvo:

Ou foi a Musa que te instruiu, a filha de Zeus, ou foi Apolo,

Pois cantas com muito esmero o destino dos Aqueus,

Quanto fizeram, sofreram e quanto labutaram os Aqueus;

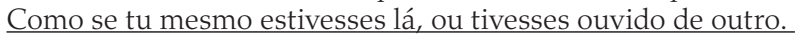

Tratados posteriores de retórica colocarão a noção de enárgeia - esta capacidade de por diante dos olhos da audiência um retrato distante-como uma das principais qualidades da ékphrasis.

\footnotetext{
${ }^{4}$ Ver Eust. I.270; Demetr. Eloc. 209.

${ }_{5}^{5}$ Todas as traduções, exceto quando especificado, são de minha responsabilidade. A edição utilizada para as traduções de Homero é a de Allen (1922). Para os fragmentos elegíacos de Sólon, Teógnis e Tirteu, utilizou-se a edição de West (1992). Para Progymnasmata de Hélio Teão, a edição utilizada foi a de Patillon 1997; para Demétrio de Falero, Russell 1995.
} 
Lemos, por exemplo, nos Progymnasmata de Hélio Teão (118.6 e 119.27) que a enárgeia é uma das virtudes da ékphrasis:

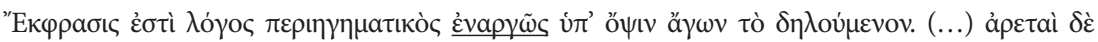

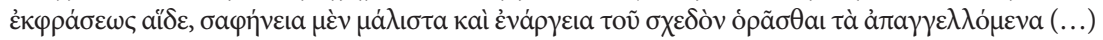

Ékphrasis é o discurso descritivo que traz vividamente (enargós) diante dos olhos o que é mostrado (...). E estas são as virtudes da ékphrasis: clareza, sobretudo, e a vividez (enárgeia) de quase fazer visível os acontecimentos relatados.

Nesse caso, não é estranho, portanto, que a poesia homérica - da qual uma das características essenciais é a presença de enárgeia - fosse pensada em sua totalidade como ecfrástica, ou seja, uma vívida descrição de detalhes, eventos e ações específicas, e que para a audiência desses poemas não existisse uma distinção bem marcada entre narração e descrição.

Essa consideração acerca da vividez da poesia de Homero permitenos aproximá-lo de outro poeta arcaico, que embora tenha tratado de temas similares, exerceu-os em outro gênero e ocasião: refiro-me ao poeta espartano Tirteu.

\section{A ENÁRGEIA NA ELEGIA GREGA: O FRAGMENTO 1o W DE TIRTEU}

Segundo Maria Noussia em Solon the Athenian, The Poetic Fragments, ${ }^{6}$ as estratégias poéticas demonstradas nas elegias de Tirteu diferem substancialmente daquelas vistas em poetas do mesmo gênero.

Sólon e Teógnis, por exemplo, pouco se detêm em imagens elaboradas: em suas elegias, é mais frequente que uma imagem seja construída a partir de comparações com fenômenos da natureza ou apelando para o senso comum, buscando antes um reforço emocional para a argumentação que o poeta deseja levar a cabo do que uma visualização precisa da cena. Exemplos são os versos 14-15 do fr. $13 \mathrm{~W}$ de Sólon, no qual se tece uma metáfora entre a perdição (ätn, áte) e o fogo (13.14-15 W), e os versos 113-14 da Teognideia, que sugerem que o interlocutor fuja do homem vil (какòv ảvíp, kakón anér) como se foge de um porto de má ancoragem:

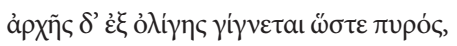

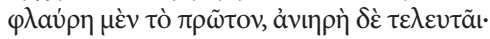

De começo fraco, [a perdição] faz-se qual chama:

reles no início, mas aflitiva no final. (Sólon 13.14-15 W) 


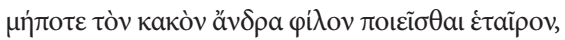

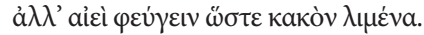

Nunca faça do homem vil um amigo querido: evita-o sempre, como a um porto ruim. (Teognideia, 113-4)

Nos exemplos citados acima, tanto Sólon quanto Teógnis partem de conceitos abstratos, que são explicados por meio de figuras concretas e comuns a seus interlocutores. Assim, por meio de símiles que remetem a situações cotidianas ou a elementos do mundo natural, estes poetas pretendem esclarecer conceitos pouco familiares à sua audiência. Nas comparações acima citadas, os poetas não se detêm em longas descrições capazes de avivar na imaginação uma cena: o intuito parece, antes, fazer com que a audiência construa a analogia proposta em prol do argumento que se deseja desenvolver.

Tirteu, por outro lado, faz com que sua audiência reconheça as suas imagens como parte de uma tradição compartilhada, um código de conduta heroico que é apresentado como herdado do passado e que é relembrado em descrições minuciosas. $\mathrm{O}$ fragmento $5 \mathrm{~W}$ é exemplar ao mostrar o intuito de sua poesia. O que Tirteu quer retomar em seus poemas é a Esparta dos ancestrais, os "pais de nossos pais":

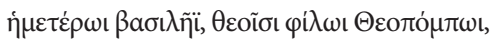

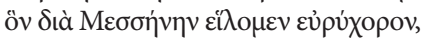

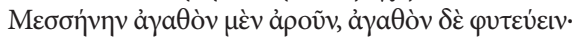

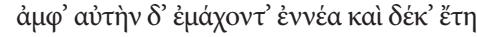

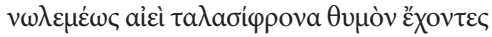

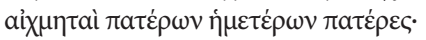

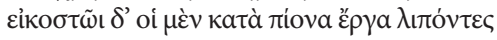

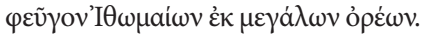

Ao nosso rei Teopompo, dileto dos Deuses, graças ao qual conquistamos vasta Messênia,

Messênia boa p'ra arar, boa p'ra plantar; por ela lutavam dezenove anos

sem trégua, sempre de coração pertinaz,

Os lanceiros pais de nossos pais;

ao vigésimo, os messênios deixaram as férteis lavouras e fugiram dos altos montes de Itome.

Um exemplo singular de como o poeta procede nesse intento é o fragmento 1o W. Nele, afirma-se um paradigma de toda a elegia exortativa marcial:

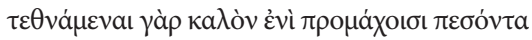

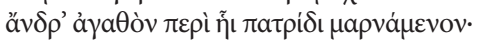

Belo, sim, é morrer, na vanguarda caindo

um varão valoroso em luta pela pátria. 
Para Tirteu existe um único curso de ação que é ka入óv (kalón, "belo") cair em batalha enquanto se luta nas primeiras filas. O poeta, porém, não demonstra a sua afirmação, mas se empenha em descrever uma série de ações opostas àquela recomendada por ele:

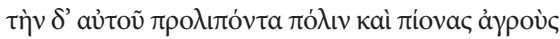

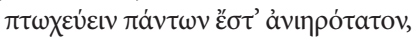

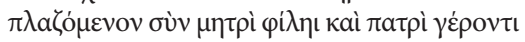

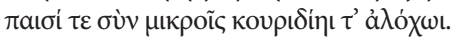

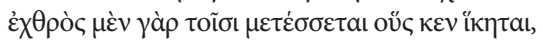

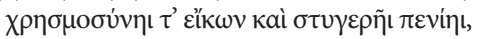

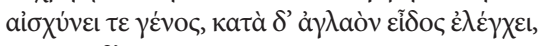

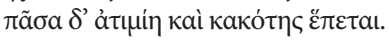

Mas mendigar, deixando sua cidade e férteis campos, de tudo é o mais penoso,

vagando com a cara mãe e o velho pai, filhos pequenos e esposa legítima.

Será odioso entre aqueles a quem chegar, pois cede à carência e à pobreza horrível, envergonha a linhagem, vexa a forma esplêndida e toda a desonra e vileza o seguem.

Tirteu conclui a imagem no verso 10 e dirige as primeiras exortações nos versos seguintes (11-14). Contrapondo-se à imagem do guerreiro errante, $\mathrm{o}$ poeta afirma que a melhor alternativa é adentrar o combate, e ratifica assim a validade universal do preceito exposto no vv.1-2 (10.11-14 W):

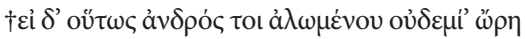

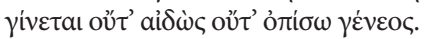

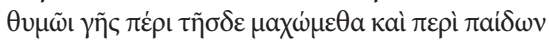

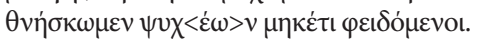

Se é assim, se ao varão errante não vêm préstimo ou respeito algum, nem à descendência, com ânimo por esta terra lutemos, e pelos filhos morramos, não mais poupando a vida!

Como observam Prato $(1968,53)$ e Maria Noussia em "Lo Stilo Semplice di Tirteo?" (2010b, 17), a poesia exortativa de Tirteu tem como característica elaborar exortações inspiradas por uma visão de mundo heroica. Como se trata de uma visão de mundo já transmitida e conhecida pela tradição, o poeta não precisa explicar os conceitos éticos nos quais essas exortações se fundam, mas procura justificá-las por meio de descrições extremamente vívidas, que acessam conhecimentos que já são compartilhados por toda a sua audiência. Noussia (2010b, 19) identifica esse procedimento 
como enárgeia e salienta a sua eficácia retórica, cujo resultado é a identificação e a criação de um elo emocional entre autor e público, que compartilham de uma mesma visão.

Uma poesia que dá tamanha importância à enárgeia - cuja principal característica é por diante dos olhos da audiência um retrato distante ${ }^{7}$ - estaria em casa no simpósio, que tem como uma de suas características a atribuição de papéis ou de situações apenas imaginadas pelos seus participantes. ${ }^{8}$

\section{HOMERO E TIRTEU}

Mas em que medida as elegias de Tirteu podem se aproximar da poesia épica, ambas dotadas de enárgeia? Nesse sentido é interessante observar os versos 21-30 do fr.1o W de Tirteu, que remetem a versos da Ilíada:

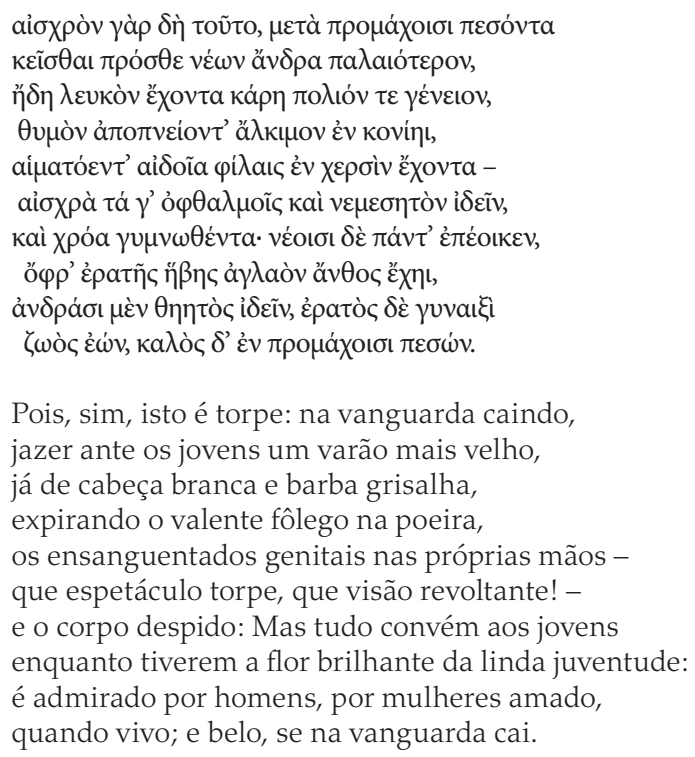

Com uma imagem extremamente bem construída, Tirteu relata nesses versos a morte aviltante que recai a um guerreiro mais velho, que assume o lugar daquele que recua do combate. Se já vimos nos primeiros dez

\footnotetext{
${ }^{7}$ Ver Bowie 1990, 222.

${ }^{8}$ Ver Bowie 1986, 17.
} 
versos desse poema o destino do jovem que foge à morte e tivemos um vislumbre de quão horrível será seu exílio, agora temos uma nova perspectiva, interna ao combate: o jovem que abandona a luta também abandona os

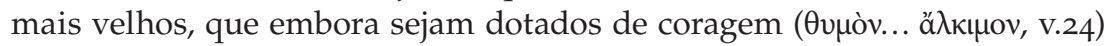

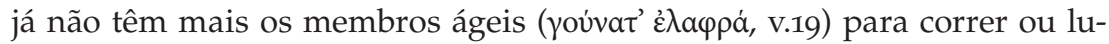
tar, pois esse é um privilégio daqueles que possuem a "flor esplêndida da

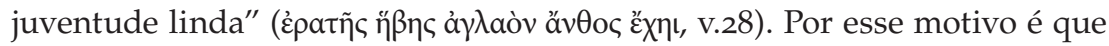
Tirteu classifica a fuga como "vergonhosa" (aỉoxpóc).

A passagem, como se disse, é fortemente reminiscente da epopeia homérica. Os versos 21-30 de Tirteu se relacionam, tanto na linguagem quanto na temática, com o pedido de Príamo a Heitor em Ilíada, 22.71-6:

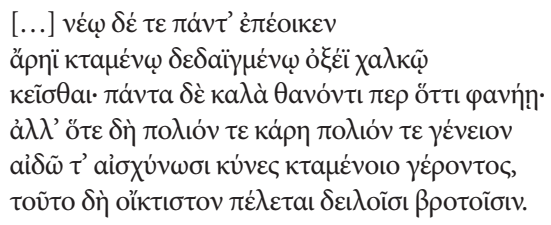

[...] Mas tudo convém ao jovem:

na guerra assassinado, trucidado por agudo bronze,

jazer. Nele, morto embora, é belo tudo que se mostra:

mas quando a cabeça grisalha e a barba grisalha

e as genitais de um ancião assassinado os cães desfiguram,

isso sim vem a ser o mais deplorável para os pobres mortais.

Apesar das passagens apresentarem suas particularidades, aceitamos que há uma conexão entre elas por causa de duas referências específicas que ocorrem em ambas: a visão brutal e reprovável do ancião dilacerado em suas partes intímas, e o espetáculo, sempre belo, do jovem que é morto em combate no viço da juventude. Para a maioria dos editores de Tirteu, cenas como essa sugeriam antes de tudo a inépcia do poeta espartano em imitar um passo de Homero, eivando-o de repetições de conceitos, argumento esse que possivelmente teria encontrado respaldo em testemunhos de autores antigos. ${ }^{9}$ Essa crítica ecoa até os tempos atuais, aonde lemos, para citar como exemplo, o que é dito por Douglas E. Gerber no seu Companion to Greek Lyric Poets, apresentando Tirteu: “(...) é verdade que não é um poeta da primeira categoria. As transições de seus argumentos às vezes são estra-

9 Pausânias (Paus. 4.15.6) assevera que Tirteu era um professor de letras que parecia ter

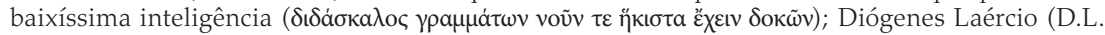

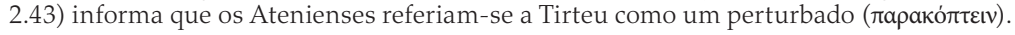


nhas, há certo grau de enchimento e ele não é avesso a repetições". ${ }^{10}$ Contudo, parece-nos que o papel dessas repetições é fundamental na poesia de Tirteu para obter maior expressividade e vivacidade nos seus argumentos, um papel que será sublinhado por Demétrio de Falero, em manual de retórica muito posterior a Tirteu (Demetr. Eloc. 211):

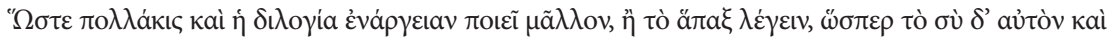

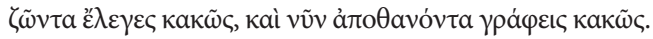

De modo que muitas vezes também a repetição torna a vividez (enárgeia) maior do que dizer uma só vez, como na frase: "Quando ele era vivo, tu falavas coisas más dele; e agora, com ele morto, escreves coisas más dele".

Além disso, não é possível identificar qual das passagens tem prioridade. Mülder ${ }^{11}$ foi o primeiro a considerar a possibilidade de que a passagem pertencesse originalmente a Tirteu e tivesse sido imitada posteriormente pelo aedo iliádico, tendo seu propósito inicial alterado, e essa teoria parece ser retomada por Martin L. West em The Making of Iliad. ${ }^{12}$ Os versos 71-3 da Ilíada seriam em princípio um encorajamento ao jovem para morrer na guerra, de maneira similar a uma exortação elegíaca - um dos escólios ao verso explica que tudo que se apresenta no jovem que morre é belo (v.73), "porque belo é morrer pela pátria e pela propriedade, em benefício dos presentes". ${ }^{13}$

A Ilíada, contudo, teria transformado a exortação em um quadro cruel do destino de Príamo - que diferentemente de seu par tirtaico, não é um guerreiro - e em um apelo à fuga feito a Heitor (vv. 73 - 76), enquanto Tirteu manteria a intenção original ao oferecer o contraponto perfeito entre a desgraça brutal do velho e a morte do jovem. O jovem morto é belo tanto do ponto de vista moral, pois assumiu o lugar seu devido no combate e protegeu "pai, filhos e esposa" (10.6W) bem como é belo do ponto de vista estético, suscitando desejo nas mulheres e admiração nos homens (10.29 W). A morte de um velho, porém, é vergonhosa, feia moralmente (um dos

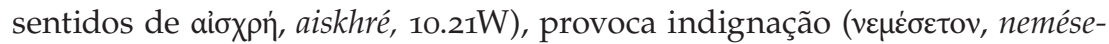
ton, 10.26W), e é horrível de se ver (outro sentido de aỉoxpí, 10.26W).

A despeito de entrar na questão de qual passagem teria primazia, notemos que na construção desta imagem Tirteu se valerá de imagens pre-

\footnotetext{
${ }^{10}$ Gerber 1997, 106: "(..) it is true that he is not a poet of the first rank. Transitions are sometimes awkward, there is some degree of padding, and he is not averse to repeat himself".

${ }^{11}$ Mülder 1906 apud Scott 1908, 123.

${ }^{12}$ West 2011, 385.

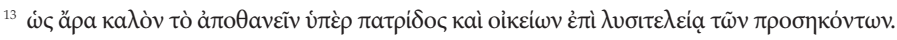




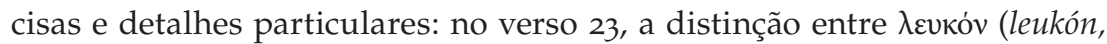

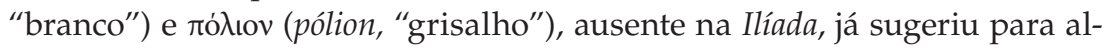
guns estudiosos, como C.M.Dawson (1966) e C. Prato (1968) a intenção do poeta em especificar, detalhar, e assim conferir maior qualidade gráfica e realismo à cena: a profusão de cores indicada pelo branco mais radiante de

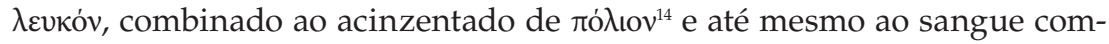
pondo a imagem no verso 25 , criam na mente do ouvinte um efeito vívido e uma cena rica em detalhes.

No verso 25, o quadro do velho segurando as suas partes íntimas cheias de sangue surpreende por seu realismo, e é bastante rara e peculiar à Ilíada. Nas diversas cenas de combate do épico, este tipo de ferimento é raramente retratado, mas há motivos para acreditar que fosse muito comum na guerra arcaica, pois a conformação da armadura deixava exposta e vulnerável a área entre o umbigo e a virilha. ${ }^{15}$ Mas dentre todas as narrativas iliádicas, apenas na morte de um guerreiro chamado Adamante é que se pode entrever algo similar (Il. 13. 566-8):

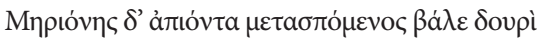

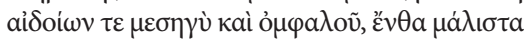

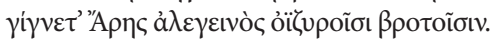 \\ Meríones seguia, em seu encalço, e atirou com a lança \\ Entre os genitais e o umbigo, lá onde Ares \\ é doloroso demais para os miseráveis mortais.
}

É interessante notar esse detalhe não só para enfatizar como Tirteu costumava traçar retratos mais realísticos da guerra, mas também porque o realismo da cena contribui para o efeito geral de enárgeia que o poeta deseja imprimir: levando em conta a definição de enárgeia proposta por certos manuais de retórica (refiro-me especificamente à obra Sobre o Estilo de Demétrio) é característica da enárgeia a descrição precisa e detalhista, onde são mencionadas todas as circunstâncias de um fato e nada se omite (Demetr. Eloc. 209):

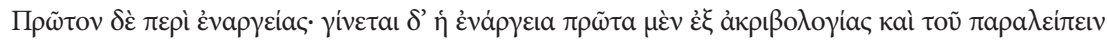

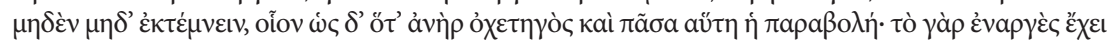

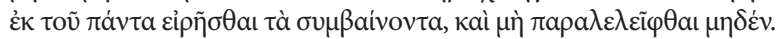

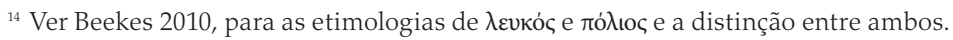

${ }^{15}$ Hans van Wees $(1994,135-6)$ informa que a couraça geralmente deixava desprotegida o baixo ventre e é justamente por isso que alguns guerreiros a reforçavam com um cinturão ( $(\omega \sigma \tau$ tí $\rho$, zostér). Ver Martino e Vox 1996, 563. 
Primeiro, [tratemos] da vividez [enárgeia]: ela ocorre, em primeiro lugar, em consequência de um discurso rigoroso, que não omite nem corta nada, por exemplo: "Como quando um homem desvia a corrente da água..." (Il.21.257), e toda essa comparação. Pois se tem a vividez ao falar de todo o acontecimento, e não deixar nada omitido.

Notemos ainda outros recursos presentes em Tirteu e não em Homero: o anacoluto do verso 26, interrompendo a descrição do veterano ferido, explicita uma força alocutória inexistente no discurso de Príamo na Ilíada. Tirteu volta-se diretamente para os seus interlocutores, e o uso da expressão ỏ $\varphi a \lambda \mu$ oĩ î́cĩv (ophtalmoîs ideîn, "ver com os olhos", v.26) sugere ao público que visualize a cena, como se pudesse estar lá de fato. Esse expediente, aparentemente único na elegia de Tirteu, ressalta a presença dos interlocutores do poeta, pedindo explicitamente que a audiência visualize com a imaginação o que é dito pelo poeta. O objetivo parece ser o de confundir, por meio de enárgeia, a audiência com soldados atuando no campo de batalha.

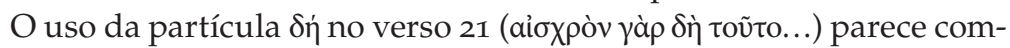
provar essa intenção e prever a força alocutória que o poeta empreenderá na imagem que se segue nos versos 22-30: segundo Bakker (1997, 75) a partícula $\delta$ ń, além de ser uma partícula confirmativa, também é empregada como um marcador evidencial, ou seja, o uso de $\delta$ ń sinaliza que o falante pressupõe que sua audiência é capaz de observar a mesma situação do que ele e, mais do que isso, sugere que ambos compartilham de um mesmo ambiente. No caso, este ambiente compartilhado é o campo de batalha, gerado pelo discurso extremamente vívido do poeta.

Como já notamos, a enárgeia pode ser aduzida como um traço da poesia de simpósio, uma vez que é capaz de evocar na mente do ouvinte, por meio de descrições precisas e detalhadas, um cenário distante. No caso da poesia de Tirteu, em que esse cenário distante é construído a partir de detalhes já presentes na tradição e compartilhados como a herança cultural de um mesmo grupo, poderíamos então propor que a sua poesia, rica na elaboração de imagens, poderia favorecer uma apropriação simpótica ou identificar o simpósio como uma de suas ocasiões de performance principais.

\section{REFERÊNCIAS}

Allen, T.W. 1920. Homeri Opera Tomo I: Iliadis Libros I-XII. Oxford: Oxford University Press.

Allen, T.W. 1920. Homeri Opera Tomo II: Iliadis Libros XIII-XXIV. Oxford: Oxford University Press. 
Allen, T.W. 1922. Homeri Opera Tomo III: Odysseae Libros I - XII. Oxford: Oxford University Press.

Bakker, E. 1997. Poetry in Speech: Orality and Homeric Discourse. Ithaca/London: Cornell University Press.

Bowie, E.L. 1986. "Early Greek Elegy, Symposium and Public Festival" in JHS 106: 13-35.

Bowie, E.L. 1990. "Miles Ludens? The Problem of Martian Exhortation in Early Greek Elegy". In Sympotica. A Symposium on the symposium, edited by O. Murray, 2209. Oxford: Oxford University Press.

Beekes, R. 2010. Etymological Greek Dictionary. Leiden/Boston: Brill.

Dawson, C.M. 1966. "Random Thoughts on Occasional Poems". YClS 19: 39-76.

Gerber, D. 1997. A Companion to Greek Lyric Poets. Leiden: Brill.

Malta Campos, A. 2007. Platão: Sobre a Inspiração Poética (Íon) e Sobre a Mentira (Hípias Menor). Tradução. Porto Alegre: L\&PM.

Martino, F.; Vox, O. 1996. Lirica greca II: lirica iônica. Bari: Levante.

Noussia, M. 2010a. Solon, the Athenian: the Poetic Fragments. Leiden/Boston: Brill.

Noussia, M. 2010b. "Lo Stilo Semplice di Tirteo?' In Les noms du style dans l'antiquité gréco-latine, edited by P. Chiron and C. Levy, 11-24. Louvain/Paris/Walpole: editions Peeters.

Patillon, M., ed. 1997. Aelius Théon: Progymnasmata. Paris: Les Belles Lettres.

Prato, C. 1968. Tirteo: Introduzione, testo critico, testimonianze e commento. Roma: Edizioni dell' Ateneo.

Russell, D., ed. 1995. Aristotle: Poetics; Longinus: On the Sublime; Demetrius: On Style. Cambridge: Harvard University Press.

Scott, J. A. 1908. "Review: Homer und die altionische elegie by Dietrich Muelder". CPh 3: $123-4$.

Van Hees, H. 1994. "The homeric way of war and the hoplite phalanx (II)". G\&R 41.2: 135-55.

West, M. L., ed. 1992. Iambi et Elegi Graeci ante Alexandrum Cantati. Oxford: Oxford University Press.

West, M. L. 2011. The Making of the Iliad. Oxford: Oxford University Press.

\section{*}

Title. Enargeia and Early Greek Elegy

Abstract. This text has two objectives: first, aims to show how the notion of enargeia, founded and developed in the Greek rhetorical tradition of fifth century, occurs in Greek poetry since the Homeric poems. Then, it tries to understand this notion in sympotic archaic Greek elegy, especially in the work of the spartan poet Tyrtaeus.

Keywords. Tyrtaeus, Elegy, Symposium, Homer. 